\title{
Dental implant stress analysis with selected prosthetic crown overhangs sizes
}

\author{
Agnieszka Lagoda $^{1 *}$, and Adam Niesłony ${ }^{2}$ \\ ${ }^{1}$ Opole University of Technology, Faculty of Mechanical Engineering, Department of Machine Technology and Production Automation, \\ Mikołajczyka 5, 45-271 Opole, Poland \\ ${ }^{2}$ Opole University of Technology, Faculty of Mechanical Engineering, Department of Mechanics and Machine Design, Mikołajczyka 5, \\ 45-271 Opole, Poland
}

\begin{abstract}
Dental implantology is one of burgeoning methods of teeth loss reconstruction. Because each patient is different, there are still many problems to be solved. One of them is occurrence of prosthetic crown overhangs. The overhangs increase the stress value and risk of the glue shattering, causing a crown fall out and requiring another implantologist's appointment. The aim of the study is to assess the stress value generated in the dental implant using Finite Elements Method and simplified models.
\end{abstract}

\section{Introduction}

Nowadays, a continuous increase in demand for dental implantology services is observable. Dentistry which is dealing with the methods of replenishing teeth loss, is one of the fastest flourishing area of medicine. The first world-spread information about tooth implants have been realised merely 30 years ago, when the scientist named Per-Irvin Brånemark published a scientific paper about this subject. As a first person describing this issue, he focused on osseointegration problems and trouble connected with metal implant screw integration with animal bone [1]. The paper concerned not only esthetical values of implantology, which still are the main reason for any patient to opt for a dental implant as a method of dental treatment. It has also begun research in osseointegration and became the initiation of works on biology aspects of implant installation. Additionally, there is a group of mechanics, carrying out their research on the mechanical aspects of teeth loss in oral cavity treatment process. This is their contribution to constant development of dental implantology and introduction fundamentals of new discipline named biomechanics.

There are still many problems to solve for dentist and biomechanics around the world. The methodology of dental implant installation process is sufficiently advanced to guarantee the reliability and safety of implant use [2], but there is a lot of unquestioned issues, especially with individual patients' cases.

The success of implantation therapy depends on many factors. The most important are [3-5]:

- the progress of the installation process affecting implantation stabilisation,

- the progress of the osseointegration process (that is the integration between the implant and the patient's bone),

- the quality of patient's bone,

- appropriately selected dimensions of the implant screw.
The aim of this study is to present the stress level generated into a dental implant construction. The Finite Element Method was used with a simplified model of dental implant with a selected range of prosthetic crown overhangs sizes.

The use of FEM in silico research is becoming increasingly popular [6]. This method works well in the very first step of teeth replenishing - treatment planning. Finite Elements Method supports the initial evaluation of the treatment success level, before the operation on the patient [7]. At the computerisation stage it is possible to eliminate the possible problems related to choosing the wrong implant geometry or unsuitable prosthetic crown overhangs size and shape. It also enables optimisation of the implantation system [8].

Commonly used implant system consists of following elements: abutment, connecting screw, implant screw (fig. 1). Prosthetic crown is connected to abutment by adhesive.

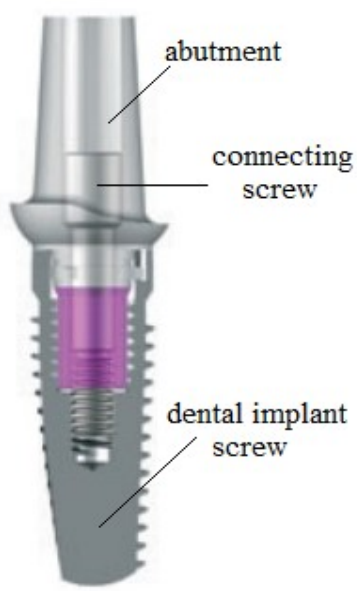

Fig. 1. Dental implantation system with its parts [9].

\footnotetext{
* Corresponding author: a.lagoda@po.opole.pl
} 
The level of success in treatment depends on plenty of dependences and factors, of course. First, there is an implant stability problem and every trouble connected with the patient bone and the implant installation. The Finite Element Method could be helpful assuming that every process is proceeding correctly. It can be only used to help in assessment of the decision, either using selected implant geometry or changing it at the very primary stage of treatment.

\section{Methods and materials}

\subsection{CAD Modelling}

Dental implant is a screw usually made from a titanium alloy. It is screwed directly into the patient mandible or maxilla. After the recovery process (approximately 3-6 months), the implant becomes a support for the prosthetic crown.

There are two kinds of dental implant: one-piece and two-pieces. They are different in terms of their construction and installation processes. Two-pieces implant consists of implant screw and separated abutment, which is connected to implant by connecting screw and becomes a pillar for the crown [10]. The onepiece implant consists of one element - implant and abutment belong together and are inseparable.

One model was used to the Finite Elements Method analysis. Two-pieces implant model was common in screw length and diameter. Model was designed such as real implants manufacturing by CAMLOG ${ }^{\circledR}$ Company. Autodesk Inventor Professional 2017 has been used to CAD modelling.

Model length and diameter are: $1=16 \mathrm{~mm}$ and $\varnothing=6 \mathrm{~mm}$ (fig. 2). Selected geometry is an image of screw geometry offered by CAMLOG ${ }^{\circledR}$ Company in their implantation systems [10].

The overhang is a part of crown which is beyond the implant screw. There are two kinds of overhangs:

- one-side - the overhang is only on one side of implant screw,

- two-side - the overhang is on two sides of implant screw.

Premolars and molars teeth as five, six, seven or eight are quite large and much larger even than the $\varnothing 6 \mathrm{~mm}$ which is the biggest diameter among CAMLOG ${ }^{\circledR}$ implants [10]. It is a natural matter for those teeth. There is a problem when the overhang is too wide - especially on one side. Then the impact of force in jaw is strong enough to shatter the adhesive. This is the reason why the crown can fall out, which leads to a necessity to visit dentist again and change the prosthetic crown shape and adhesive it on abutment one more time. Repeated visit does not ensure a successful treatment. New tooth crown very often falls again and there is a need to see a doctor for several times. Overhangs are amongst the most problematic issues in implantology, as well as osseointegration trouble, implant stabilisation or implant installation problems, or lack of bone to qualify the patient to operation.
Research includes one-side overhang in sizes of $0 \mathrm{~mm}$ and $3 \mathrm{~mm}$. Fig. 3 presents the parts of implantation system for crown without overhang. Fig. 4 shows the parts of implant system for crown with $3 \mathrm{~mm}$ overhang. Furthermore, the parts are divided for elements and prepared to the Finite Elements Method analysis.

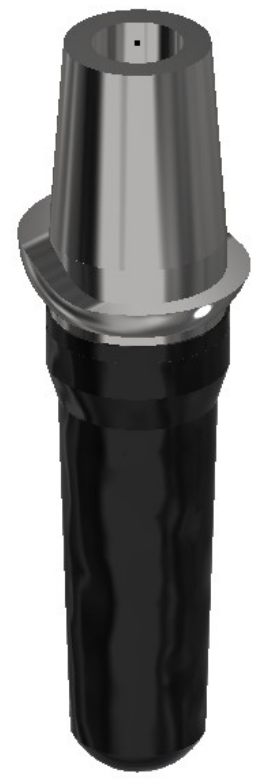

Fig. 2. Dental implant model without tooth crown.

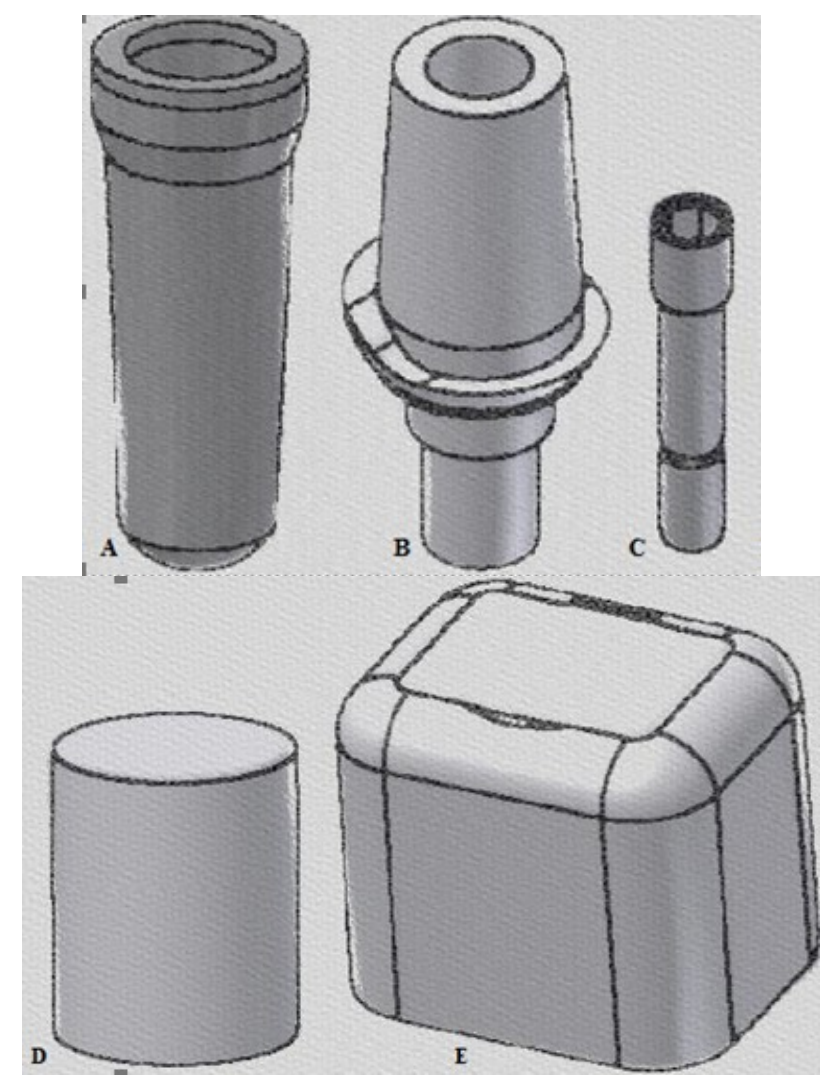

Fig. 3. Dental implant system parts, where A - implant screw, $\mathrm{B}$ - abutment, C - connection screw, D - adhesive layer, E prosthetic crown without overhang [11]. 


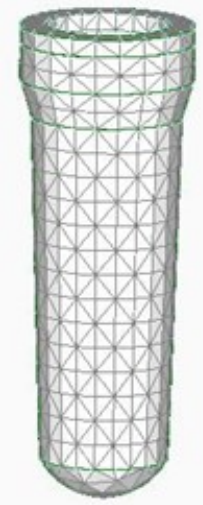

D

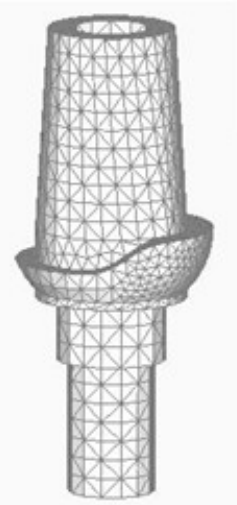

B

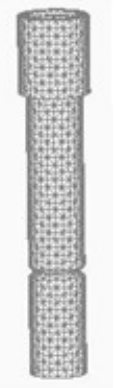

C
A

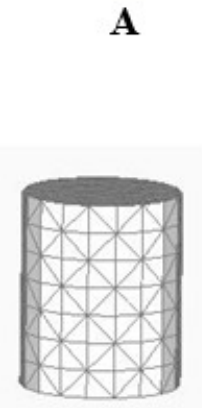

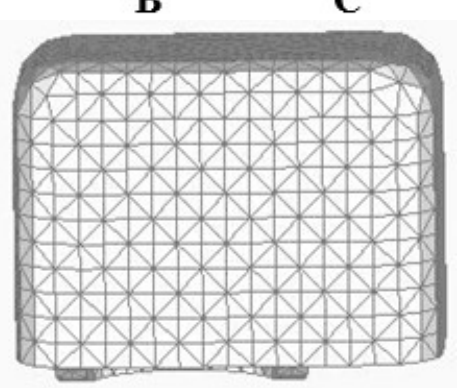

$\mathbf{E}$
Fig. 3. Dental implant system parts with elements, where A implant screw, B - abutment, C - connection screw, D adhesive layer, E - prosthetic crown with $3 \mathrm{~mm}$ one-side overhang [12].

\subsection{Material properties}

It was assumed that the implant was made of titanium and more specifically, the titanium alloy named Ti6Al4V. This material is very popular and used by CAMLOG ${ }^{\circledR}$ because of good strength properties and no negative impact on the human body [10]. This alloy is characterised by greater resistance to fatigue compared to pure titanium. It is also indifferent to the difficult conditions prevailing in human oral cavity [13]. Those are very eligible properties for biomaterial.

However, at present titanium alloy $\mathrm{Ti} 4 \mathrm{Al} 4 \mathrm{~V}$ is less often used due to the content of vanadium in its composition. There are several reports on hazardous effects of this material on a human body [14]. As replacement for this type of alloy, the Ti6Al4V ELI alloy is becoming increasingly popular. The content of harmful elements is reduced in this alloy [15]. In terms of material properties, both alloys do not differ from each other. Their modulus of elasticity and Poisson's ratios needed for research remain at the same level [16]. Any change of material does not affect obtained results. It has an impact on patient's condition.

Cobalt-chromium alloy is the most commonly used metal material in metal construction, for instance abutment and connection screw. Young's module is on high level which is $220 \mathrm{GPa}$ [7]. The material is mainly valued for its anti-corrosive properties and no negative impact on the human body. The chromium content increases the hardness of steel and has a significant role in the alloys used for prosthetic tools. This application of chromium in larger amounts $(12 \div 30 \%)$ provides corrosion resistance. Cobalt increases hardness of steel [17].

The RelyX Unicem dental adhesive is the most commonly used adhesive by implantologists. It is a composite cement characterised by the absence of etching of the glued surface. It only needs rinsing and drying. This is a self-etching adhesive, so it is less durable than bonding materials requiring special surface preparation [18]. However, the lack of eugenol in glue content and zinc oxide base make the product extremely versatile. It can be used not only for adhesiving a tooth crown on an abutment, but also as a precise replacement for cavities. The adhesive provides a strong bond to tooth and dental materials [19].

The most frequently used material for dental crowns is zirconium oxide. Research on its use in dentistry dates back to the 90 s of the twentieth century [20]. Zirconium oxide has many positive aspects that are used in dentistry. The most important of these are: corrosion resistance, mechanical strength, high hardness and the highest bending strength of dental and prosthetic materials [21]. Due to zirconium oxide high costs, standard dental ceramic becomes more and more popular. Its properties are eligible enough to perform an operation. It is cheaper and this material is adopted to analysis.

Each item of implant system was assigned to the appropriate material. The properties are shown in the table 1. Ti6Al4V ELI is material for dental implant screw, cobalt-chromium alloy for abutment and connection screw, adhesive for adhesive connection between abutment and tooth crown and dental ceramic is for tooth crown.

Table 1. Material properties [7, 13, 22].

\begin{tabular}{|c|c|c|}
\hline Material & $\begin{array}{c}\text { Young's } \\
\text { Modulus [GPa] }\end{array}$ & Poisson's ratio \\
\hline Ti6Al4V ELI & $\mathrm{E}=110$ & $\mathrm{v}=0.32$ \\
\hline $\begin{array}{c}\text { Cobalt- } \\
\text { chromium alloy }\end{array}$ & $\mathrm{E}=220$ & $\mathrm{v}=0.3$ \\
\hline Adhesive & $\mathrm{E}=3.9$ & $\mathrm{v}=0.35$ \\
\hline Dental ceramic & $\mathrm{E}=61.2$ & $\mathrm{v}=0.19$ \\
\hline
\end{tabular}

\subsection{Boundary conditions}

The analysis was carried out for few forces [23]:

- 20N - force for chewing food,

- $100 \mathrm{~N}$ - popular force repeated in literature,

- 157,7N - force acting on premolar tooth no. 35 [5],

- 196N - force acting on molar tooth no. 36 [5],

$-200 \mathrm{~N}$ - maximum bite force in healthy human jaw,

- $500 \mathrm{~N}$ - maximum bite force in unhealthy human jaw (bruxism).

There were six analyses of crown without overhang model and consecutive six analyses for crown with overhang model. Force was set perpendicular to the corner of overhang at implant models with overhang crown. For tooth crown without overhang, force was set perpendicular to the crown surface (green arrows in the fig. 4). 
Glued contacts were used as a connection between elements of FEM model.

The linear analysis was carried out in FEMAP program with NX Nastran modulus implemented inside. The nonlinearity geometry was not taken into consideration, because there was no need for that. Discretisation of each object for finite elements was conduct in FEMAP program also. There were 37296 tetra-shaped elements for model without the overhang and 38298 for model with overhang.

Both models were constrained along the dental implant screw surface. Models were fixed to facilitate research and keep behaviour of dental implant after correct osseointegration process with the bone. Black triangles correspond with fixed constrain of each model in the fig. 4 .

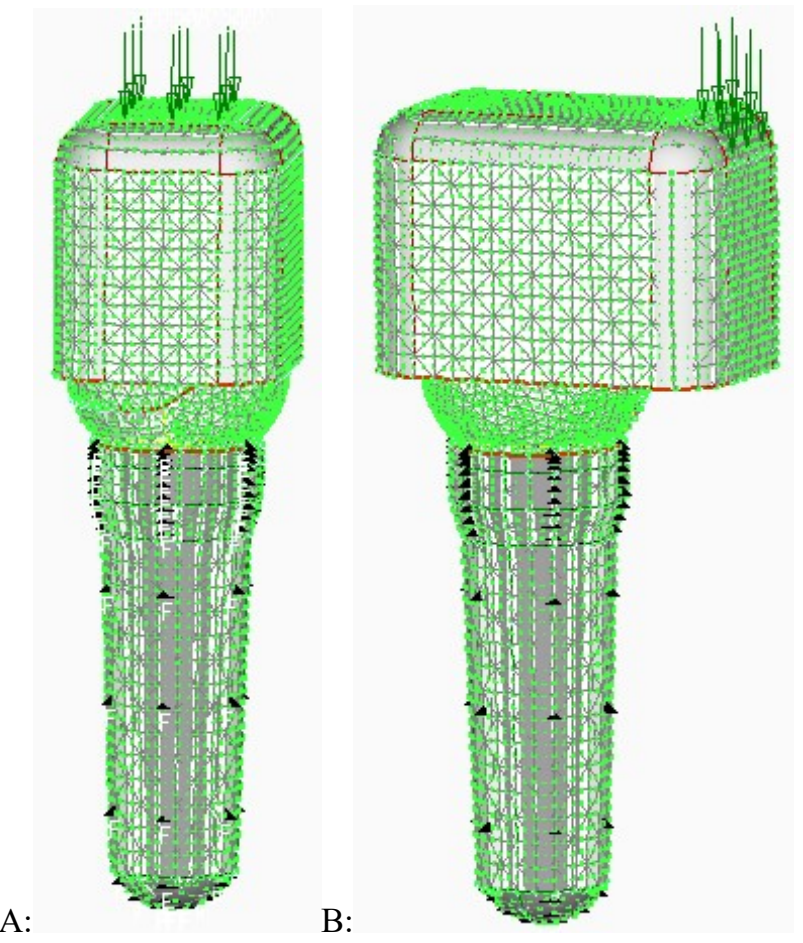

Fig. 4. Models boundary conditions, where green arrows show the load place and direction and the black triangles represent the fixed constrains. A - model without the overhang, B model with one-side overhang.

\section{FEM stress analysis}

\subsection{Model without overhang}

In the fig. 5, the stress analysis of tooth crown section without overhang is presented.

The maximum reduced stress, according the HuberMises hypothesis, is in an upper part of model - between the abutment and adhesive layer. There are also results for side part of connection between implant screw and abutment. It comes from the specific shape of abutment characteristic for CAMLOG ${ }^{\circledR}$ implant system.
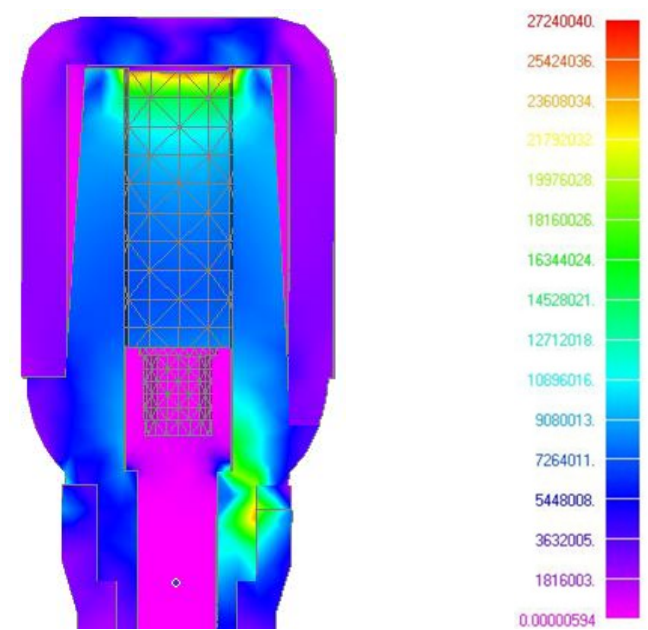

Fig. 5. Result for section of dental implant without overhang for $200 \mathrm{~N}$.

\subsection{Model with one-side overhang}

In the fig. 6 , the stress analysis of tooth crown with overhang is depicted.
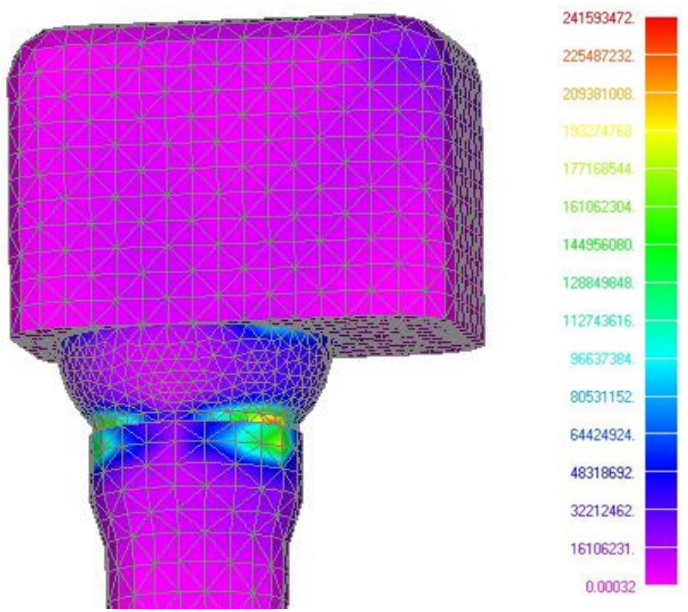

Fig. 6. Result for dental implant with $3 \mathrm{~mm}$ one-side overhang for $200 \mathrm{~N}$.

The maximum stress, according the Huber-Mises hypothesis, is in a part of model between the abutment and implant screw.

\section{Results and conclusion}

The results of linear stress analysis are compared in the table 2. The most precarious results are for $500 \mathrm{~N}$ force. This force is assign for ill people with occlusion parafunctions, such as bruxism. Generally, this group of patients is not qualified for dental implant treatment; nevertheless, after medical consultation and positive opinion, they could be considered for replacement of the teeth loss using implants. 
Table 2. Results for stress analysis.

\begin{tabular}{|c|c|c|}
\hline \multirow{2}{*}{ Force } & \multicolumn{2}{|c|}{$\begin{array}{c}\text { Maximum reduced stress } \\
\text { according to Huber-Mises } \\
\text { hypothesis }\end{array}$} \\
\cline { 2 - 3 } & $\begin{array}{c}\text { without } \\
\text { overhang }\end{array}$ & with overhang \\
\hline $\mathbf{2 0 N}$ & $2.7 \mathrm{MPa}$ & $24 \mathrm{MPa}$ \\
\hline $\mathbf{1 0 0 N}$ & $13.5 \mathrm{MPa}$ & $120 \mathrm{MPa}$ \\
\hline $\mathbf{1 5 7 , 5 N}$ & $21.3 \mathrm{MPa}$ & $190 \mathrm{MPa}$ \\
\hline $\mathbf{1 9 6 N}$ & $26.5 \mathrm{MPa}$ & $236.2 \mathrm{MPa}$ \\
\hline $\mathbf{2 0 0 N}$ & $27 \mathrm{MPa}$ & $241 \mathrm{MPa}$ \\
\hline $\mathbf{5 0 0 N}$ & $67.5 \mathrm{MPa}$ & $602.5 \mathrm{MPa}$ \\
\hline
\end{tabular}

There is maximum reduced stress according to HuberMises hypothesis bar graph with comparison of stresses between no overhang and overhang model shown in the fig. 7. Clearly, the value of stress generated under $500 \mathrm{~N}$ force impact is almost ten times greater with overhang application than without.

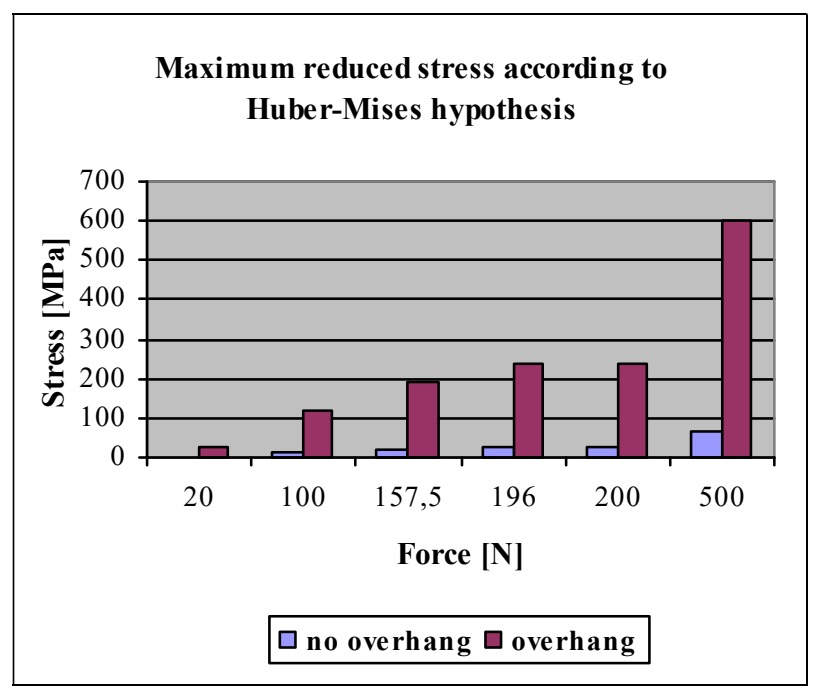

Fig. 7. A bar graph with comparison of model without overhang stress and model with one-side overhang stress.

The overhangs are very typical problems to struggle with in dentistry. FEM can be helpful to assess the level of treatment success, assuming that every installation and osteointegration problems proceed fortunately. The model was constrained along with the implant screw surface. It reflected the implant set inside the bone. In these conditions, the research revealed that $3 \mathrm{~mm}$ overhang for person with occlusion parafunction could be dangerous and there was a need to assess the treatment success more precisely. More than $600 \mathrm{MPa}$ stress level can be the reason for tooth crown falling out or even the abutment damage.

\section{References}

1. P-I. Brånemark, Osseointegration Book: from Calvarium to Calcaneus, 1. edit, Berlin; Chicago: Quintessence Pub. Co. (2006).

2. G. Wang, X. Gao, E. Lo, J. of Dent. 43 (2015).

3. W. Chladek, Biomechanika Inżynierska Narządu Żucia. Zagadnienia Wybrane, Gliwice (2008)

4. R. J. Lazzara, JIRD 1 (2012).

5. G. Milewski, Wytrzymałościowe Aspekty Integracji Biomechanicznej Tkanka Twarda - Implant Stomatologiczny, Kraków (2002).

6. J. Geng, K. Tan, G. Liu, J. Pros. Dent. 85 (2001).

7. O. Kayabasi, E. Yuzbasioglu, F. Erzincanli, Adv. Eng. Soft . 37 (2006).

8. A. Dobosz, H. Panek, P. Napadłek, Dent. Med. Probl. 42 (2005).

9. Camlog Compedium, 1. Surgery, Thieme Verlagsgruppe (2007).

10. Camlog, Conelog ( Implant System, Product Catalog (2012).

11. A. Materac, A. Niesłony, APB 11 (2016).

12. A. Materac, A. Niesłony, APB 9 (2016).

13. B. Jedynak, E. Mierzwinska-Nastalska, Dent. Forum 1 (2013).

14. J. Marciniak, Biomateriaty, Wyd. Pol. Sl., Gliwice (2002).

15. Y. Okazaki, S. Rao, Y. Ito, T. Tateishi, Biomaterials 19 (1998).

16. ISO 5832-3, Implants for surgery - Wrought titanium-6 aluminium-4 vanadium alloy. ASTM F136 - Specification for Titanium -6Al-4V ELI, Alloy for Surgical Implant Applications.

17. Z. Bańkowski, Mały poradnik mechanika. WNT, Warszawa (1976).

18. M. Prylicki, P. Deręgowska-Nosowicz, H. Shaw, E. Kaczmarek, Dent Med Prob 43 (2006).

19. 3M Espe, RelyX product catalog.

20. H.J. Conrad, W.J. Seong, I.J. Pesun, J. Prosthet. Dent. 98 (2007).

21. K. Lasek, P. Okoński, E. Mierzwińska-Nastalska, Prot Stom 6 (2009).

22. M. Marzec-Gawron, S. Michalska, B. Dejak. Prot Stom 3 (2012).

23. M. Idzior-Haufa, W. Hędzelek, Sz. Rzątowski, P. Gajdus, M. Rychlik, Prot. Stom. 6 (2013). 